\title{
Formas dA GRAMÁtica RenAscentista: \\ PERCEPÇÃO E ABORDAGEM DA DIVERSIDADE \\ LiNguística EM Fernão de Oliveira
}

\section{(Grammar forms in the Renaissance period: perception and a linguistic diversity approach in Fernão de Oliveira)}

\author{
Ronaldo de Oliveira BATISTA \\ (Universidade Presbiteriana Mackenzie)
}

\begin{abstract}
Taking as a parameter linguistic historiography methodologies (as the relationship between 'climate of opinion' and language production), the article reconstructs and interprets approaches to linguistic variation, perceived and discussed by Fernão de Oliveira, in the first grammar of Portuguese (1536). In search of building a linguistic identity, the pioneer grammarian sought, in the peculiar characteristics of the language, basis for the affirmation and elevation of the national character of the Portuguese people. With these in mind, this case study aims to locate Oliveira's study in a grammatical tradition typical of the sixteenth century Renaissance period.
\end{abstract}

Key-words: linguistic historiography; Renaissance; linguistic variation.

Resumo: Partindo de diretrizes teórico-metodológicas da Historiografia Linguística (como a relação entre clima de opinião e produção linguística), o artigo reconstrói e interpreta abordagens da variação linguística, percebida e comentada por Fernão de Oliveira, na primeira gramática da língua portuguesa (1536). Em busca da construção de uma identidade linguística, o pioneiro gramático procurou nas particularidades do idioma bases para afirmação e elevaçãa do caráter nacional do povo português. Procura-se, a partir desse estudo de caso, situar o trabalho de Oliveira numa tradição gramatical renascentista típica do século XVI.

Palavras-chave: historiografia linguística; Renascimento; variação linguística. 


\section{INTRODUÇão}

Este texto, resultado de reflexões anteriores ${ }^{1}$ sobre elementos da gramática renascentista, procura rever aspectos da obra gramatical de Fernão de Oliveira que destacam a percepção do gramático sobre a variação linguística e suas formas de tratamento. Destaca-se também de que modo esses aspectos puderam ser utilizados com fins políticos e ideológicos, no sentido de terem estabelecido a diversidade e unidade do povo português (e sua língua) diante dos outros Estados nacionais que se formavam na Europa ocidental renascentista. Como interesse retrospectivo do artigo, coloca-se a reconstrução historiográfica de uma tradição do pensamento gramatical subjacente à produção de gramáticas vernaculares no século XVI.

\section{História da linguística, HiSTORIOGRAFIA LiNGUísticA E Fernão de Oliveira}

A presença de Fernão de Oliveira na história dos estudos sobre a linguagem e as línguas é inquestionável, cabendo a ele o título de primeiro descritor da língua portuguesa em forma de gramática, ainda que ressalvas possam ser colocadas a esse título, uma vez que o próprio Oliveira reconheceu seu trabalho como anotações. Daí a possibilidade, presente em vários estudiosos, de situar a primeira gramática na obra de João de Barros, especificamente com a publicação de 1540. Ao lado do controvertido aspecto de pioneirismo, a figura de Oliveira ainda ganha destaque pela efeméride que representa o final do primeiro decênio dos anos 2000, quando se comemoram quinhentos anos de nascimento do gramático.

Procurando essencialmente delinear formas do fazer gramatical de uma das tradições do período renascentista (aquela que deu origem a gramáticas vernaculares pioneiras, muitas delas de feição pedagógica), realizo a seguir um estudo de caso a partir de propostas teórico-metodológicas da Historiografia Linguística como forma de análise de eventos da história do pensamento gramatical português, destacando a relação entre aspectos

1. Em dois trabalhos anteriores, publicados em 2001, refleti sobre o tratamento da diversidade linguística em Fernão de Oliveira. Como esses trabalhos tiveram circulação restrita (como folder de apresentação de exposição e como publicação em anais de evento), tomei a liberdade, considerando uma circulação mais ampla no debate linguístico, de retomar pontos de análise e de interpretações conclusivas. 
internos da gramática e aspectos externos à obra, ou seja, seu contexto social, histórico e político (o clima de opinião de produção da gramática).

Para delinear com mais cuidado o caminho teórico, cabe dizer que a Historiografia Linguística, como disciplina descritiva e analítica, não é coextensiva à história dos eventos da linguística ${ }^{2}$. Esses são movimentos da história empreendida pelos homens, em determinados contextos, com intenções sociais, educacionais, culturais, políticas e ideológicas. A observação historiográfica na linguística visa, então, problematizar esses eventos, colocando-os numa perspectiva de análise que procura destacar o papel que tais eventos desempenharam na emergência e nos desenvolvimentos de posicionamentos, descrições de fatos da língua, recortes analíticos ao longo do desenrolar da história do saber linguístico. Cabe, assim, situar o papel de Fernão de Oliveira na gramaticografia portuguesa.

\section{LÍNGUAS NACIONAIS, O PORTUGUÊS E O RENASCIMENTO LINGUÍSTICO}

No século XVI, momento crucial da formação e desenvolvimento de algumas das nações europeias, a afirmação e elevação dos idiomas nacionais foram pontos fundamentais para caracterizar a unidade e possível hegemonia de uma nação.

Portugal é um caso exemplar desse espírito da época. Foi nos quinhentos que a nação portuguesa colocou-se como referência política e econômica no arranjo europeu, e o idioma português passou a ser um dos elementos centrais do processo de afirmação da unidade e também da diversidade portuguesas diante de outros povos e línguas.

Os primeiros gramáticos da língua portuguesa, Fernão de Oliveira (1507-1580/81?) e João de Barros (1496?-1570/71?), foram defensores da singularidade de sua língua materna, vista por eles como superior a todas as outras, inclusive ao latim, língua da qual se tinha originado.

2. Ao empregar o termo 'linguística', refiro-me a todas as formas de estudo a respeito de línguas e linguagem, inclusive aquelas que se situam historicamente muito antes do período de institucionalização de uma disciplina Linguística, como é o caso do material em análise neste artigo. 
Nesse ambiente de patriotismo e louvor à língua, esteve em destaque a questão do enfrentamento da língua do outro, na qual qualquer manifestação linguística diversa da do português poderia ser vista como inferior.

Autor das primeiras descrições gramaticais (ou anotações) do português, Fernão de Oliveira, em 1536, na sua Grammatica da lingoagem portuguesa, atuou como paladino da língua que iniciava seu processo de gramatização ${ }^{3}$. Nas suas colocações, destacou-se a necessidade de firmar o português como superior, uma vez que seus falantes são superiores. Em busca da execução desse objetivo, até o latim, reconhecido como língua-mãe, teve seu papel relativizado, já que o uso da língua portuguesa deveria ser privilegiado, num contexto histórico e político que ampliava sobremaneira a urgência do reconhecimento de uma nação independente: “... porque melhor é que ensinemos a Guiné que sejamos ensinados de Roma, ainda que ela agora tivera sua valia e preço" (Oliveira 1975[1536]: 42).

Já João de Barros deixou aflorar, segundo Buescu (1978), todo o patriotismo não na sua obra gramatical, mas no Diálogo em louvor da nossa linguagem, complemento da sua Grammatica da lingua portuguesa de 1540.

Adotando postura semelhante à de Oliveira, Barros reconheceu identidades entre português e latim, de caráter formal, para principalmente facilitar o processo de aprendizagem da língua (uma vez que a gramática latina era objeto de estudo).

Que se póde desejár na língua portuguesa que éla [não] tenha? Conformidáde com a latina?

[...] se póde ver quanta tem, porque assi sam portugueses, que ôs entende o português, e tão latinos, que ôs não estranbará quem soubér a língua latina. (Barros 1971[1540]: 397)

Barros assumiu a idéia de que era preciso demonstrar muito mais diferenças entre português e latim - estabelecidas, na gramática, por cons-

3. Esse momento corresponde ao que Auroux chama de "... gramatização [...]. Podemos formulála assim: o Renascimento europeu é o ponto de inflexão de um processo que conduz a produzir dicionários e gramáticas de todas as línguas do mundo [...] na base da tradição greco-latina. Esse processo de 'gramatização' mudou profundamente a ecologia da comunicação humana e deu ao Ocidente um meio de conhecimento / dominação sobre as outras culturas do planeta. Trata-se propriamente de uma revolução tecnológica que não hesito em considerar tão importante para a história da humanidade quanto a revolução agrária do Neolítico ou a Revolução Industrial do século XIX" (Auroux 1992: 8-9). 
tantes comparações entre as línguas - do que identidades. Mais uma vez, a unidade do português era garantida pela sua diversidade. Nas palavras de Buescu, a avaliação do que o gramático estabelecia como relação entre português e latim:

a filiação latina da língua portuguesa e a conformidade desta com ela constituem, sem dúvida, títulos de nobreza e um dos motivos de louvor da língua portuguesa, patentes no Diálogo, mas não deixa de reconhecer a individualidade do Português em relação à língua-mãe. (Buescu 1978: 63)

Perseguindo o ideal de elevação da nação portuguesa e de seu povo, Oliveira e Barros colocaram-se como combatentes ao enfrentar a língua castelhana, vista como a língua do outro que deveria ser enfrentada e combatida. Não se pode esquecer aqui das causas e consequências de um momento histórico que acabaria por levar Portugal ao domínio espanhol de 1580 a 1640, além do bilinguismo português/castelhano presente. Fatos que autorizaram, para os gramáticos, a necessidade da insistência na afirmação da diversidade e superioridade do português em relação ao castelhano. Como cada um combate com as armas que tem, Oliveira e Barros utilizaram o ofício de gramático para impor o que eles julgavam ser próprio da nação portuguesa.

Buescu (1978: 68-69) aponta que para Barros a questão de enfrentar o castelhano era necessária, inclusive pelo prestígio que esta língua tinha como meio de expressão da literatura e da cultura, tanto que o gramático enfrentaria essa rivalidade na escrita do Diálogo em louvor da língua portuguesa. Rivalidade acentuada quando os gramáticos se davam conta da semelhança (de caráter lexical e gramatical) entre as duas línguas. Portugueses e espanhóis lutavam não só politicamente, mas também se enfrentavam, de forma dura, no campo linguístico, numa disputa que poderia ser caracterizada pela máxima: a minha língua é melhor porque, antes de qualquer coisa, não é a língua do outro.

... a prolaçám e ár que temos da linguágem, diferente das outras nações, temos no módo de cantar, cá mui estranha compostura é a françesa e italiana e espanból ... (Barros 1971[1540]: 399)

Sobre o enfrentamento português vs. castelhano, diz Buescu:

Ora o binómio português/castelhano, aparentemente adversativo do binômio latim/português, traz, afinal, a neutralização deste, na medida em que a posição em relação ao castelhano 
releva duma praxis: apresenta a iminência de um risco que os humanistas pressentem - o do predomínio da língua competitiva, forma de expressão de uma nação de algum modo rival -e em termos objetivos mais poderosa - no plano político interno e também no plano duma política expansionista e imperial. (1983: 225)

Um dos métodos adotados pelos gramáticos no tratamento da diversidade entre as línguas foi o de marcar, pela produção sonora dos falantes, a peculiaridade do português. Como se os gramáticos quisessem reforçar que era na pronúncia que uma língua se diferenciava da outra, fato importante se lembrarmos da situação de bilinguismo da época. Se havia semelhanças lexicais e gramaticais entre os idiomas, existiam, de maneira mais diretamente perceptível, diferenças na pronúncia dos sons, na articulação destes, na forma de falar. E é esse o método escolhido pelos gramáticos e defensores do português para marcar sua língua em oposição à do outro ${ }^{4}$.

João de Barros fez uso do mesmo método de análise da língua do outro, no Diálogo em louvor da nossa linguagem, para marcar a diversidade portuguesa:

F(ilho) - Daí viria logo o provérbio que dizem: Espanhóis chóram, Italianos uivam, Franceses cantam.

$P$ (ai) - Bem adequaste o provérbio [...] E, para um francês formar um seu próprio ditongo, faz nos beiços esgares que póde amedrontar meninos, cousa de que um natural orador fóge. E, por não cair neste perigo, rodea setenta vocábulos. Certo assim a francesa, como a italiana, mais parecem falas para mulheres, que grave para homens [...] Nesta gravidade, como já disse, a portuguesa léva a todas, e tem em si uma pureza e sequidão para cousas baixas [...]. A linguagem portuguesa, que tenha ésta gravidáde, nam pérde a força para declarár, mover, deleitár e exortár, a parte a que se enclina, seja em quál género de escritura. (Barros 1971[1540]: 400)

Barros também se colocou em oposição em relação ao vasconço, galego e cigano (considerados piores do que a língua a ser prioritariamente enfrentada, o castelhano), indicando o primeiro como exemplo de caos gramatical, como afirma Buescu (1978: 72).

4. Sobre a constante referência a fenômenos do plano sonoro da língua nos gramáticos do Renascimento, diz Buescu (1983: 37): "Assim, a Gramática que, num plano mental nascera com a lógica, sucedendo à averiguação especulativo-filosófica pura, separa-se dela, para se infixar numa diferença, e nasce, em segundo nascimento, num plano técnico, com a Gramatologia. Assenta num axioma básico, a partir do momento em que a cultura ocidental faz a grande opção dum alfabeto fonético e supõe, num itinerário explorativo, a indagação, em primeiro lugar, do nivel fonológico da linguagem, isto é, da sua segunda articulação" (grifo meu). 
a grande variedade de suas linguágens [dos habitantes das ilhas de Maluco] cá nam lhe chega o vasconço da Biscaia, de maneira que um lugar não se entende com outro.

Todos [teólogos, filósofos, matemáticos, juristas, médicos] entre si trazem termos que nam sam latinos nem gregos, mas quase um vasconço.

... os que falam vasconço, que trocam umas letras por outras ...

... a língua castelhana muito melhor é que o vasconço de Biscaia e o çeçear cigano de Sevilha, as quáes nam se pódem escrever. (Barros 1971[1540]: LII-LIII)

Em meio a empreendimentos em busca da elevação do português, a época também conheceu certo desprezo pelo idioma, apontado como possuidor de características desprezíveis, entre elas a pobreza vocabular. As opiniões negativas foram rebatidas por João de Barros, que definiu motivos de grandeza da língua: riqueza vocabular'; filiação latina; gravidade e majestade; sonoridade agradável (utilizando aqui critério de avaliação semelhante ao de Oliveira); capacidade de abstração, possível alargamento do vocabulário por meio de empréstimos.

Oliveira justificou a superioridade de sua língua nos seguintes termos:

As nossas vozes acabam sempre em voz perfeita e desimpedida, o que não consentem as letras mudas, mas, ao contrário, atam a boca e cortam as dicções, que é próprio de mudos e grosseiros, como vemos quase nas gentes de terras frias ... (Oliveira 1975[1536]: 67)

A defesa da língua portuguesa nos quinhentos também foi objeto dos primeiros ortógrafos da língua. Pero Magalhães de Gândavo (?-1579) em 1574, no Diálogo em Defesa da Lingua Portuguesa, colocou frente a frente um português e um falante do castelhano, envolvidos os dois em questões sobre a linguagem. No Diálogo, Gândavo ressaltou, em oposição ao castelhano, possibilidades da língua portuguesa como veículo não só do saber cultural, como também de formas da boa literatura. Semelhante caminho adotou Duarte Nunes de Leão (ca. 1530-1608), na Orthographia da Língua Portuguesa (1576) e na Origem da Lingua Portuguesa (1606), que, entre ou-

5. Segundo Buescu, na introdução à sua edição da obra gramatical de João de Barros, o gramático acabaria por reconhecer que o português teria vocabulário mais pobre que o grego e o latim (Buescu apud Barros 1971[1540]: XXXI). 
tros aspectos, ressaltou a dificuldade da língua portuguesa. Como aponta Buescu (1978: 50), no século xvi, a dificuldade de uma língua era sinal de nobreza e, consequentemente, superioridade em relação a outras línguas que não possuíssem tal "qualidade".

\section{A primeira gramática da língua portuguesa}

Como já apontamos, a Grammatica da Lingoagem Portuguesa (1536) de Fernão de Oliveira ${ }^{6}$ ocupa (não sem polêmicas), na história do pensamento gramatical, o lugar da primeira publicação de uma descrição do português, que então atingia o status de língua nacional europeia e passava pelo processo da gramatização.

A obra de Oliveira não segue com rigor o modelo clássico ocidental para o formato de uma gramática ${ }^{7}$, sendo caracterizada como um conjunto de descrições e reflexões, não exatamente sistematizadas, sobre a língua portuguesa.

Em 50 capítulos, a gramática trata da definição de língua, com referências às origens da nação e língua portuguesas, da definição de gramática, da fonética (talvez a parte que mais desperte interesse, não só pela extensão - 23 capítulos - mas também pela exemplificação abundante de fenômenos fonéticos do português da época), da lexicologia (com destaque para uma discussão sobre etimologia, numa breve reconstrução da história do léxico português), dos estudos das partes do discurso (metalinguagem utilizada na época para o tratamento das classes de palavras), da morfologia (entendida aqui como a abordagem de fenômenos morfossintáticos, de declinações seguindo o tão presente modelo greco-latino e também da

6. Gramático português, foi funcionário da corte portuguesa, pedagogo em Évora, Lisboa e Coimbra. Teve formação dominicana, sendo dissidente dessa congregação, que o perseguiu, fazendo com que Oliveira se tornasse uma espécie de refugiado ao longo de sua vida. Viajou para a Itália (1540-1), para a Inglaterra (1545), foi prisioneiro em Portugal durante três anos; viajou, ainda, para o norte da África em 1552. Prisioneiro novamente no período 1555-1557. Morreu em 1580 ou em 1581 (Gonçalves 1998: 381).

7. A historiografia linguística reconhece a expressão "Gramática Tradicional" como equivalente ao conjunto de proposições descritivas e metalinguísticas de origem greco-latina, no período conhecido como a Antiguidade clássica ocidental. Assim, quando se empregar a idéia da utilização de um modelo latino, estaremos nos referindo a formas de descrição da língua utilizadas em gramáticas da tradição greco-latina ocidental e também em algumas gramáticas do Renascimento que se caracterizaram por dar continuidade ao modelo clássico (cf. Law 2003: 13-93; Swiggers 1997: 69-131). 
formação de palavras). Um capítulo, extremamente reduzido, sobre fenômenos reconhecidos como sintáticos encerra a gramática.

Como parte de uma história de continuidades no pensamento linguístico, é importante lembrar que uma vertente da tradição gramatical da Antiguidade clássica ${ }^{8}$ e de gramáticas latinas do Renascimento - obras que se colocam em diálogo com as descrições do período de gramatização da língua portuguesa - também se caracterizaram por não apresentar ampla descrição de aspectos sintáticos. Pode-se dizer que, de fato, a tradição gramatical que nos interessa neste trabalho concentrou-se mais nas questões que diziam respeito às partes do discurso. Assim, o tratamento reduzido da sintaxe é comum para uma das formas de tratamento gramatical no período renascentista (desconsidera-se aqui outra tradição, que privilegiou de maneira diferente a análise da parte sintática ${ }^{9}$ ), pois a descrição e análise linguísticas observadas em pioneiras gramáticas vernaculares, como as portuguesas, construíram-se em torno da palavra, o que acabaria por limitar abordagens sintáticas a fenômenos subordinados a construções lexicais. Ou seja, essas abordagens da sintaxe tinham por base o estudo da palavra em situação de discurso, sendo que a concepção latina de discurso, fonte de saber para muitos dos gramáticos do Renascimento, é uma concepção morfológica. Há uma sintaxe organizada em torno da palavra, das relações estabelecidas pelo nome (substantivo e adjetivo) e pelo verbo, com atenção para os fenômenos de concordância e regência (Batista 2002: 112-119).

Dentro desse formato gramatical, as reflexões (em algumas passagens, Oliveira refletiu, de fato, sobre a língua portuguesa, sua origem e seu papel

8. É preciso ressaltar que autores dessa tradição clássica apresentaram preocupações com a sintaxe. Não se pode considerar que o pensamento gramatical caminhou no período em um bloco único. Lembra-se, por exemplo, do gramático grego Apolônio Díscolo e do latino Prisciano, que colocaram em suas obras destaque para a abordagem da parte sintática da língua.

9. A tradição de estudos sintáticos da Idade Média, aquela de caráter especulativo, não teve continuidade nas gramáticas pedagógicas do Renascimento (pelo menos não naquelas consideradas como exemplares da codificação gramatical do português). Há gramáticos que, de alguma maneira, seguiram a tradição medieval dos estudos sobre a linguagem ou propuseram uma forma de ver a língua diversa da daquela tradição observada neste texto, e que entre outros aspectos privilegiaram de maneiras diferentes o tratamento da sintaxe. Entre esses autores estão nomes como Sánchez de las Brozas [1523-1600], Pierre de La Ramée [1515-1572], Thomas Linacre [1460-1524]). Esses autores influenciariam, no século XVII, outra tradição de fazer gramatical, a que daria origem às teorias da universalidade linguística, tal como prevista pela Grammaire Générale et Raisonée (1660) de Port-Royal. 
no novo cenário europeu) e descrições de Oliveira foram realizadas, seguindo imperativos do clima de opinião (elevação da nação), tendo em vista a afirmação da unidade da língua portuguesa. O que vemos é o constante posicionamento de marcar a autonomia do português em relação ao latim e de assinalar peculiaridades em relação às outras línguas conhecidas.

Não somente nestas, mas em muitas outras coisas tem a nossa linguagem vantagem, porque ela é antiga, ensinada e próspera e bem conversada e também exercida em bons tratos e ofícios. (Oliveira 1975[1536]: 39)

Dessa maneira, a escrita da Grammatica, preocupada em transmitir o que seria o bom uso da língua, na tentativa de fundação de uma norma de prestígio para o idioma, interessou-se mais pela demonstração de um sistema coeso e coerente, uma vez que uma nação, também coesa e coerente, devia possuir um idioma que pudesse representar a essência de seu povo.

Assim, é de esperar que uma descrição gramatical que tivesse esse tipo de objetivo não apresentasse descrições detalhadas de variantes do que estava sendo proposto como padrão de uso prestigioso para o português, já que se procurava registrar e mostrar a unidade linguística. No entanto, Oliveira descreveu fenômenos de diversidade intralíngua, ou seja, de diferentes realizações do português europeu e também fez comentários a respeito da diversidade do português em relação a outros idiomas.

... cada um fala como quem é: os bons falam virtudes, e os maliciosos, maldade; os religiosos pregam desprezos do mundo e os cavaleiros blasonam façanhas. (Oliveira 1975[1536]: 38)

... mas uma mesma nação e gente de um tempo a outro muda as vozes e também as letras. (id.:46)

E não somente a ortografia é diversa em diversas línguas, mas também em uma mesma língua se muda com o costume. (id.:65)

A história das ciências da linguagem nos mostra que não é a gramática o locus preferencial para o tratamento de diversidades linguísticas (a gramática coloca de forma paradoxal a relação entre norma e uso da língua), mas quando analisamos a gramática de Oliveira podemos ver que, em muitos momentos, a questão da unidade e da diversidade foi abordada. Descrições gramaticais do momento histórico da formação dos Estados nacionais europeus apresentam comentários sobre a diversidade, seja ela 
referente a outros idiomas, seja com referência a variações (decorrentes de fatores como tempo, espaço geográfico, situação social) diante do que estava sendo proposto como padrão de uso. O aspecto paradoxal é que algumas gramáticas surgiram como instrumento de controle da diversidade, já que era necessária a existência de um idioma unificado para legitimar uma nação, mas a origem dessa unidade está ligada à diversidade, uma vez que esta é que incute a necessidade de padronização (cf. Kibbee 1990).

Nesse sentido, a diversidade era um dos tópicos do fazer gramatical do momento renascentista, sendo que seu registro foi o que contribuiu para a afirmação de novos padrões de uso da língua. O período teve de enfrentar uma questão ainda sem solução nas reflexões sobre o pensamento gramatical: como lidar com a diversidade linguística em uma obra que se coloca como o registro da norma?; como observar a norma diante da diversidade?; quem confere valor à norma? Acrescenta-se a essas questões o fato de que o Renascimento colocava diferentes vernáculos diante da necessidade de serem escritos e codificados pela primeira vez. Tendo essa dimensão em vista, a questão da norma, do uso e da variação coloca-se de forma ainda mais conflitante (cf. Leite 2007).

A seguir, o tratamento da diversidade linguística na gramática de Fernão de Oliveira é analisado historiograficamente, tendo em vista o português do século XVI, outros idiomas europeus e reflexões e métodos empregados pelo gramático no registro dessa diversidade.

\section{O tratamento da diversidade linguística em Oliveira (1536)}

Ao tratar da diversidade linguística, Fernão de Oliveira privilegiou aspectos do português presentes nos planos fonético, lexical e morfossintático da língua. Entre eles:

a) aspectos fonéticos: a diversidade e a forma como sons eram produzidos são consideradas como parâmetros de análise. São feitas observações sobre a articulação dos sons no português e em outros idiomas, e também são feitas considerações a respeito da percepção dos sons produzidos;

b) aspectos lexicais: análise da diversidade em relação a escolhas de itens lexicais, com a descrição de variações diastráticas, diatópicas e diacrônicas do português da época; 
c) aspectos morfossintáticos: diferentes realizações de formas verbais são apontadas, levando-se em conta possível alteração na estrutura morfossintática, relacionada ou não a fenômenos de caráter sonoro.

\subsection{Oliveira e a diversidade entre idiomas: a questão da nacionalidade}

Ao abordar a diversidade em relação a outros vernáculos, o gramático utilizou como critérios diferenciadores a produção sonora dos falantes (a articulação e percepção dos sons), a anatomia do aparelho fonador dos habitantes de determinada região, o costume no uso da língua, o país de origem. Todos esses critérios são associados ao caráter dos homens.

Vemos formar diversas as vozes, umas ciciosas, outras tártaras e muitas com muitos defeitos e também com perfeições. Porque, como este órgão da língua e boca é mais e melhor disposto, assim cumpre melhor seu ofício. Bem ou mal disposto pode ser em qualidades e feição, qualidades como seco ou búmido, feição como dentes grandes ou desviados; e também muitos falam muito mal só com mau costume, não mais. E é muito de culpar este defeito de as qualidades serem diversas, nas quais têm domínio as condições de céu e terra em que vivem os homens. Vem que umas gentes formam suas vozes mais no papo, como Caldeus e A rábigos, e outras nações cortam vozes, apressando-se mais em seu falar, mas nós falamos com grande repouso, como bomens assentados. (Oliveira 1975[1536]: 39)

Oliveira demonstrou preocupação com a descrição dos sons e de sua articulação, inclusive com detalhes de pronúncia ("Pronuncia-se o $r$ singelo com a língua pegada nos dentes queixais de cima, e sai o bafo tremendo na ponta da língua", p.55), chegando a ser explícito quanto à escolha de um de seus métodos de tratamento da diversidade:

Examinemos a melodia de nossa língua e essa guardemos, como fizeram outras gentes, e isto desde as mais pequenas partes, tomando todas as vozes e cada uma por si e vendo em elas quantos diversos movimentos faz a boca como também diversidade do som e em que parte da boca se faz cada movimento, porque nisto se pode discutir mais distintamente o próprio de cada língua. $E$ assim é verdade, que os Gregos com os Latinos e os Hebraicos com os Arábigos e nós com os Castelhanos, que somos mais vizinhos, concorremos muitas vezes em umas mesmas vozes e letras e contudo não tanto que não fique alguma particularidade a cada um por si uma só voz e com as mesmas letras e a nós e aos Castelhanos guerra e papel. E no pronunciar quem não sentirá a diferença que temos porque eles escondem-se e nós abrimos mais a boca? [...] entre nós e os Castelhanos porque a eles deu a natureza afeiçoar o que querem dizer e nós falamos com mais majestade e firmeza. (Oliveira 1975[1536]: 47) 
O português era superior porque seus sons eram articulados mais pausadamente, resultando, portanto, numa língua de "homens assentados". Como se pode perceber, um aspecto biológico e físico (resultante da percepção e produção dos sons) é recorrentemente associado a referências sobre o caráter dos homens, numa relação constante entre o que seria a manifestação social e psicológica dos membros de uma sociedade e a produção linguística.

À distinção sonora acrescentou-se a variação regional, "condições de céu e terra", marcando, por exemplo, a diferença entre caldeus (povo do Mediterrâneo), hebreus e árabes em relação aos portugueses. Para Oliveira, a diferença entre esses povos e os habitantes das terras da nação portuguesa manifestava-se, também, pela produção de maior número de sons guturais e aspirados nas línguas dos outros povos que não os portugueses.

E nós, mais que todos, com a boca mais aberta, e as nossas vozes são mais fora da boca, o que não têm os Hebreus e Arábigos, cuja própria é aspiração, porque eles formam suas vozes dentro quase na fressura [pulmão], donde falando lançam muito espírito [ar]. (Oliveira 1975[1536]: 61-62)

Não se pode esquecer de que a superioridade da língua portuguesa, como apontada por Oliveira, era um dos instrumentos mais importantes para afirmação da autonomia nacional.

Tanto Fernão de Oliveira como João de Barros defenderam a excelência da língua portuguesa, censurada de pobreza vocabular pelos homens doutos da época. É tão extremado o nacionalismo de Fernão de Oliveira, que para ele a fala portuguesa "tem de seu a perfeyção da arte que outras naçôes adquirem de muyto trabalho" (prólogo); e mais adiante: "... e com tudo apliquemos nosso trabalho a nossa lingua e gente... e nam trabalhemos em lingua estrangeira" (cap. V). (Spina 1987: 15)

\subsection{As variantes da lingua portuguesa: no caminho da} fundação de uma norma

No trabalho de Oliveira, é possível encontrar diferentes formas de percepção da variação linguística do português do século XVI. Demonstrando consciência de que uma língua apresenta diferentes formas de realização, relacionadas a diferentes aspectos de natureza externa à língua, o gramático pontuou variações na sua língua, sem deixar de apontar, muitas vezes de forma implícita, a necessidade da escolha, dentre a diversidade, de uma forma que pudesse conferir à língua a tão almejada unidade. 
... e esta particularidade [escolha de vocábulos] ou se faz entre ofícios e tratos, como os cavaleiros que têm uns vocábulos e os lavradores outros, e os cortesãos outros e os mercadores outros.

Ou também se faz entre terras esta particularidade, porque os da Beira têm umas falas, os do Alentejo outras e os homens da Estremadura são diferentes dos de Entre Douro e Minho, porque, assim como os tempos assim também as terras criam diversas condições e conceitos. E o velho, como tem o entender mais firme, com o que mais sabe, também suas falas são de peso, e as do mancebo, mais leves. (Oliveira 1975[1536]: 98)

Sua análise observou, preponderantemente, a escolha de itens lexicais e processos morfofonéticos e morfossintáticos, caracterizadores de variedades regionais, socioeconômicas, relacionadas com a idade dos falantes, ou seja, variações diatópicas, diastráticas e diacrônicas.

Oliveira, ao afirmar que a escolha vocabular dependia de aspectos sociais, em que cavaleiros (nobres) usariam palavras diferentes daquelas escolhidas por lavradores (não-nobres), reconheceu a variação diastrática, chamada pelo gramático de "particularidade entre ofícios e tratos".

A variação diatópica também foi reconhecida por Oliveira, que a nomeou como "particularidade que se faz entre terras". Moradores de Estremadura (sul de Portugal) falavam de maneira diferente da empregada por moradores de Entre Douro e Minho (norte de Portugal). Assim como os da Beira (centro-norte) tinham "falas" diferentes das dos moradores do Alentejo (centro-sul). Oliveira, ao registrar essas diferentes "falas", apontou a existência de dialetos em Portugal. No século XVI (como até hoje), havia diferenciação dialetal entre o norte e o sul. A "fala" do sul era considerada como o dialeto-padrão ou modelar, ao contrário do "falar" do norte, marginalizado socialmente, considerado como arcaico (cf. Teyssier 1997).

Observa-se, também, a percepção da variação ocasionada pelo correr do tempo. Ao caracterizar a linguagem do "velho" como "mais firme [...] de peso", em comparação com a linguagem do "mancebo", "mais leve", o gramático demonstrou ter exemplos de ocorrência da variação linguística decorrente do fator temporal, "posto que o uso do falar tenha seu movimento, como diz Varrão, e não persevere um mesmo entre os homens de todas as idades" (p.107).

As opiniões de Oliveira sobre a variação determinada pelo fator temporal caminharam em duas direções opostas. Em alguns momentos, ele 
afirmou ser o "velho" e sua linguagem modelos para o uso do português: "E o velho com seu entender mais firme...". No entanto, em outras passagens, apresentou uma visão na qual a linguagem mais antiga seria algo a ser evitado, principalmente em relação à questão lexical.

Mas não é muito de maravilhar, diz Marco Varrão, que as vozes envelheçam, e as velhas alguma hora pareçam mal porque também envelhecem os homens cujas vozes elas são. [...] E assim como os olhos se ofendem, vendo as figuras que a eles não contentam, assim as orelhas não consentem a música e vozes fora de seu tempo e costume. (Oliveira 1975[1536]: 94)

As diç̧ões usadas são estas que servem a cada porta, como dizem. Estas, digo, que todos falam e entendem, as quais são próprias do nosso tempo e terra. E quem não usa delas é desentoado, fora do tom e música dos nossos homens de agora. (id.: 97)

$\mathrm{Na}$ citação a seguir, vemos o registro da diversidade na realização da forma verbal da $1^{\mathrm{a}}$. pessoa do singular do presente do verbo ser. Essa variação era ocorrência comum no século XVI, dada a diversidade morfofonética possível entre as realizações terminadas em -am, -om, -o, -ou ou -ao (Paiva 1988: 41).

... uns pronunciam em om [a $1^{\mathrm{a}}$. pessoa sing. pres. verbo ser], como som, e outros em ou, como sou, e outros em ao, como são, e também outros, que eu mais favoreço, em o pequeno [fechado], como so. No parecer da primeira pronunciação com o e $m$, que diz som, é o mui nobre João de Barros, e a razão que dá por si é esta: que de som mais perto vem a formação do seu plural, o qual diz somos. Contudo, sendo eu moço pequeno, fui criado em S. Domingos de Évora, onde faziam zombaria de mim os da terra, porque o eu assim pronunciava, segundo que o aprendera na Beira. (Oliveira 1975[1536]: 121)

No trecho acima, Oliveira avançou em direção a uma tentativa de padronização, afirmando que a forma so era a mais favorecida por ele, ainda que apontasse opinião diversa da sua. De fato, em alguns trechos da gramática, Oliveira mostrou-se interessado na fundação de uma norma portuguesa, principalmente em relação à ortografia. Uma norma de prestígio seria fornecida pelo "bom costume" da língua, presente nos homens cultos e "assentados", não amigos de muitas mudanças, ou seja, em meio à diversidade era preciso buscar, para o bem da língua e da nação, a unidade. O critério de seleção da variedade de prestígio, o "bom costume da língua", foi o referendado pelo uso das pessoas mais cultas, mais velhas e mais assentadas, "os que mais leram, viram e viveram". 
... saibamos que a primeira e principal virtude de uma lingua é ser clara e que a possam entender, e para ser bem entendida há-de-ser a mais acostumada entre os melhores dela e os melhores da lingua são os que mais leram e viram e viveram, continuando mais entre primores sisudos e assentados, e não amigos de muita mudança. (Oliveira 1975[1536]: 99).

\subsection{Alguns comentários em busca de sintese}

Oliveira fez considerações importantes sobre a diversidade, tanto no contexto europeu como em relação a variações na língua portuguesa. Levando em conta esse último aspecto, Coseriu (1975) refere-se à contribuição de Oliveira, caracterizando-a como uma "sociolinguística" portuguesa do século XVI, uma vez que estão presentes na gramática a percepção e o registro das variedades do português europeu quinhentista. Já em relação à diversidade interlínguas, o gramático enfatizou peculiaridades e a autonomia do português em relação a outros idiomas.

Esse posicionamento, diante da diversidade entre línguas, indicia elementos para que a historiografia possa traçar o percurso de formação e desenvolvimento, no período renascentista, de complexas relações que se desenvolveram entre diferentes tradições do pensamento gramatical, que colocariam muitas vezes em franca oposição visões de universalidade e particularidade para explicações da estrutura e do funcionamento das línguas, numa retomada, de certa forma, de debates anteriores a respeito de regras gramaticais e exceções, colocando em foco uma das grandes questões do fazer gramatical de todas as épocas: a gramática deve privilegiar a busca por analogias ou por anomalias na descrição de uma língua?

Ainda é importante lembrar que para Oliveira linguagem é fenômeno espiritual condicionado por fatores físicos e biológicos. Sendo assim, pode-se apontar que um de seus métodos de análise (observação, de natureza fisiológica, biológica e acústica, da articulação dos sons e dos órgãos envolvidos nesse processo e também da percepção sonora) além de servir para marcar a diversidade, servia da mesma forma à sua concepção de linguagem.

\section{Considerações finais: Oliveira e Formas da GRAmática RENASCENTISTA}

Oliveira é parte fundamental da tradição linguística portuguesa, representante de um período que elevou as línguas vernaculares ao estatuto 
de objetos legítimos de descrição e análise gramaticais. Seu trabalho coloca em jogo duas formas de compreender a diversidade linguística nesse momento de reorganização de espaços, fronteiras e ideologias no mundo europeu. Em uma delas, há a necessidade de afirmação do português como língua nacional autônoma, seja em relação ao latim, seja em relação a outras línguas que também buscavam sua legitimidade como idioma; em uma outra forma, há também outra afirmação, mas agora a do reconhecimento da variedade do português eleita como base para a configuração de uma norma de prestígio.

Em nome do interesse de marcar a especificidade do português frente a outras línguas, próximas por espaços geográficos ou por compartilharem aspectos históricos comuns em suas filiações, o gramático ressaltou diferenças de seu idioma em relação a outros, levando em conta pontos como articulação dos sons e ritmo da fala. Ao mesmo tempo, para assegurar a representatividade da variedade que codificava, Oliveira apontou, embora não as tivesse tomado como objeto preferencial, particularidades dialetais e socioletais de pronúncia e/ou de vocabulário que observou no uso da língua.

Ainda que este artigo não tenha tido como objetivo uma descrição e análise integral da gramática de Oliveira, mas apenas a observação do tratamento da diversidade linguística, é possível situar, por meio desse olhar, de que forma a obra de 1536 está inserida num contexto maior de publicações em torno dos modos de perceber e codificar a estrutura gramatical de uma língua.

Sendo assim, o empreendimento gramatical de Oliveira situa-se no contexto da gramatização dos vernáculos europeus do século XVI, em uma tradição estabelecida a partir da descrição de línguas baseada nas formas e métodos da escrita gramatical clássica (greco-latina) do Ocidente.

Essa tradição gramatical atualizou técnicas de sistematização originadas na Antiguidade clássica. A manutenção dessa tradição no Renascimento ocidental pode ser vista como a adoção de um caminho ideal no momento em que foi empreendida (lembre-se, por exemplo, da retomada do pensamento clássico como um dos pontos centrais da reconfiguração renascentista no campo das ideias), possibilitando a existência de gramáticas pioneiras na descrição de vernáculos até então sem codificação "oficial" da escrita. Essas obras gramaticais tinham sua transmissão garantida para conhecedores dos 
métodos de descrição tradicionais, já que o sistema e as formas educacionais colocavam em destaque o ensino do latim e da descrição gramatical da língua clássica.

Nesse processo de continuidade do uso de um método gramatical, gramáticos lançaram mão de procedimentos e estratégias que visaram à possibilidade de compreensão e transmissão didática, ressaltando a relação que línguas pudessem ter com o latim ou outros vernáculos europeus, sejam relações de natureza positiva, sejam relações de natureza negativa, visando estas últimas a afirmações de superioridade de povos, costumes e línguas. Não é à toa que veremos nessa tradição o uso extensivo da busca de equivalências nas descrições e comentários sobre línguas, bem de acordo com o espírito da época, que procurava ver e entender a realidade e seus diferentes aspectos por meio de comparação e busca de similitudes.

Para as gramáticas escritas nessa tradição, a palavra era considerada como unidade fundamental do sistema e estrutura de uma língua, ocasionando, dessa forma, extensas descrições das partes do discurso, ao lado de abordagens bastante relevantes de aspectos sonoros, em detrimento do tratamento de fenômenos sintáticos das línguas - exatamente como se pode visualizar no tratamento da diversidade linguística em Oliveira (que destacou, como vimos, os sons, a escolha lexical e estruturas morfossintáticas).

Oliveira e suas anotações gramaticais, nas palavras do próprio, possibilitam a visualização de um momento da história da gramática ocidental que se caracteriza como cumulativo e não de rupturas, mantendo, assim, saberes e métodos anteriormente adquiridos e que tiveram início na emergência das primeiras reflexões a respeito da constituição gramatical de línguas como grego e latim, nessa ordem, na Antiguidade clássica ocidental. Cabe lembrar, em palavras finais, que uma outra tradição gramatical era presente, no período renascentista, em trabalhos (que culminariam na proposta da gramática geral de Port-Royal em 1660) que dialogaram com outras esferas de influência, como aquelas que colocaram em consideração a relação pensamento/linguagem e também a questão da universalidade linguística, trilhando um caminho bem diferente daquele percorrido por Fernão de Oliveira em nome da defesa do que ele considerava como "nossa lingua" e "essoutras" no mundo europeu quinhentista.

Recebido em março de 2009 Aprovado em novembro de 2009 E-mail: ro_batista@uol.com.br 


\section{REFERÊNCIAS BIBLIOGRÁFICAS}

Altman, Cristina (coord.). (2000) O Tratamento da Diversidade Linguística. Exposição apresentada no XV Encontro Nacional da ANPOLL, na Universidade Federal Fluminense, de 4 a 7 de junho de 2000, acompanhada de folder com textos, ilustrações e bibliografia, 10pp. São Paulo: CEDOCH/DL-USP.

Auroux, Sylvain. (1992) A revolução tecnológica da gramatização. Trad. de Eni P. Orlandi. Campinas: Editora da Unicamp.

BArros, João de. (1971[1540]). Grammatica da lingua portuguesa. Edição de Maria Leonor Carvalhão Buescu, com introdução, notas e leitura atualizada. Lisboa: Publicações da Faculdade de Letras da Universidade de Lisboa.

Batista, Ronaldo de Oliveira. (2000) Unidade e diversidade em Fernão de Oliveira. In: Altman (coord.), p. 2. São Paulo: CEDOCH/DL-USP. (Republicado em Imaguire (org.), 181-182.)

BAtista, Ronaldo de Oliveira. (2001). Nossa língua e essoutras: o tratamento da diversidade linguística em Fernão de Oliveira. In: Imaguire (org.), p. 53-61.

Batista, Ronaldo de Oliveira (2002). As linguas difficultosas e os linguas peritos. Artes de gramática jesuíticas no Brasil colonial dos séculos XVI e XVII. Dissertação de Mestrado, 137f. Faculdade de Filosofia, Letras e Ciências Humanas da Universidade de São Paulo.

Buescu, Maria Leonor Carvalhão. (1978) Gramáticos portugueses do século XVI. Lisboa: Instituto de Cultura Portuguesa.

Buescu, Maria Leonor Carvalhão. (1983) Babel ou a ruptura do signo. A gramática e os gramáticos portugueses do século XVI. Lisboa: Imprensa Nacional/Casa da Moeda.

Coseriu, Eugenio. (1975) Língua e funcionalidade em Fernão de Oliveira. Rio de Janeiro: Presença.

GonçALves, Maria Filomena. (1998) Grammaires portugaises. Histoire, Espistémologie, Langage, hors-série 2.1:381-2.

Imaguire, Lígia Maria Campos (org.) (2001). As línguas do Brasil: tipos, variedades regionais e modalidades discursivas. Colaboração de Cristina Altman na organização. Seleção dos textos proferidos no III Encontro dos Alunos da Pós-Gradução em Linguística da USP em dezembro de 2000. São Paulo: FFLCH/DL/USP. 
Kibbee, Douglas A. (1990) Language variation and linguistic description in 16th-century France. Historiographia Linguistica 17:1/2.49-65.

LeITe, Marli Quadros. (2007) O nascimento da gramática portuguesa. Uso \& Norma. São Paulo: Humanitas: Paulistana.

Oliveira, Fernão de. (1975[1536]) A Gramática da Linguagem Portuguesa. 4. ed., introdução, notas e leitura atualizada por Maria Leonor Carvalhão Buescu. Lisboa: Imprensa Nacional/Casa da Moeda.

Parva, Dulce de Faria. (1988) História da língua portuguesa. v. II: Século XV e meados do século XVI. São Paulo: Ática. (Série Fundamentos) SpInA, Segismundo. (1987) História da Língua Portuguesa. v. III: Segunda metade do século XVI e século XVII. São Paulo: Editora Ática. (Série Fundamentos)

Swiggers, Pierre. (1997) Histoire de la Pensée Linguistique. Paris: PUF. Teyssier, Paul. (1997) História da Língua Portuguesa. Trad. de Celso Cunha do orig. francês Histoire de la langue portugaise de 1980. São Paulo: Ed. Martins Fontes. 